\title{
Exposure to COVID-19 is Not the Only Threat to Mental Health
}

\section{Jesús RIC*}

Senior Doctorate Student, Carlos Albizu University-San Juan Campus, Puerto Rico

*Corresponding author: Rebeca I. Carrasquillo-de Jesús, Senior Doctorate Student, Carlos Albizu University-San Juan Campus, Puerto Rico, Emails: prof.carrasquillo@gmail.com; rcarrasquillo@albizu.edu

\section{Mini Review \\ Volume 5 Issue 4}

Received Date: November 02, 2020

Published Date: December 09, 2020

DOI: $10.23880 /$ pprij-16000253

\section{Abstract}

Due to the innovation and jeopardy of the pandemic caused by COVID-19, it has been observed that the population is not treating their pre-existing health conditions as usual. It has also been observed that people, for the fear of being infected with COVID-19 and due to confinement, do not continue with their treatments of health conditions diagnosed prior to the pandemic, and it will be possible an increase, in the not too distant future, of other health conditions. Also, the health of the population, both physical and mental, can be compromised. The objective of this article is to present some of the conditions that have been observed during other epidemic episodes and some risk factors that population are currently exposed to due to COVID-19. As health professionals we have to create awareness about the importance of provide immediate attention to these mental health conditions because it could become a detrimental public health problem also, this issue can possibly be greater than the one we have today with the pandemic.

Keywords: COVID-19; Mental health threats

According to Morens, et al. (2020), COVID-19 pandemic is among the deadliest infectious diseases to have emerged in recent history [1]. Even so studies suggest, during epidemics, the amount of people whose mental health is affected tends to be greater than the people affected by the infection [24]. Also, survivors of the disease keep traumatic memories and face rejection by society when they return home, and those who never get the disease may grieve for the loss of their relatives or struggle to cope with severe anxiety [4]. Similarly, in almost all media, is common to see a great number of people talking about how the possibility of being exposed to COVID-19 is creating lot of anxiety and discomfort to them. As well, it is more common for health professionals, scientist and leaders to focus more on propose measures for preventing, containing, treating the disease and also, on how the pathogen show the symptoms and the biological risk of it. Likewise, the psychological and psychiatric implications tend to be undervalued and overlooked, this create gaps in coping strategies and increase the liability of associated diseases $[2,3]$. But when health and mental health professionals looks this phenomenon, can realize other aspects that can affect the population health. A simple example can be, thinking about social distancing \& quarantines, some people could prefer to avoid visit their doctors, started to skipping the follow-up medical appointment of their previous health conditions and could not take medications as recommended.

Nonetheless, if we think about the origin of symptoms and pathologies, it will be conditioned by multiple variables and factors. If we consider a bio-psycho-social perspective [5], we should consider the person health condition, their emotional circumstances and those of their normative group [5] before the deliberation of a diagnosis or person needs. The development of diagnosis will largely depend on psychosocial risk and must be handled by mental health professional. Gutierrez-Salegui (2020) defines psychosocial risk as the probability that a traumatic event exceeds a specific value of damage in social and mental health terms. It would be the product of the interaction between external and internal conditions, and would also be related to the presence of other risks. The external condition is what we know as the threat (COVID-19), the internal condition will 


\section{Psychology \& Psychological Research International Journal}

be the vulnerability (fears, feelings, etc.) and the other risks can be environmental factors, health condition (previous diseases) or economic status [6] (loss of job). Relatedly, when the population witnessing adverse events, such seeing the great amount of people dying because of COVID-19, or experiencing by their selves, equally, when suffer a loss of a family member or a significant other can cause a traumatic event, that can lead to adverse psychological states [6]. By other hand, in child-hood the exposure of adversity, like what there are exposed right now, was identified by Center for Disease Control and Prevention, as a primary contributing factor to a still-growing collection of physiological and emotional impairments $[7,8]$ of the children. And in adults, the stress resulting from trauma can negatively affect adult intimate relationships when one or both partners experience disruptions in the ability to communicate, manage their emotions, and engage in intimate relations $[7,8]$.

\begin{tabular}{|c|c|}
\hline Author & Mental Health Threats Examples \\
\hline Qiu et & $\begin{array}{l}\text { Young people are experiencing high levels of emotional distress nevertheless them are } \\
\text { associated to be at lower risk for COVID-19 complications. } \\
\text { The COVID-19 epidemic is associated to triggered a wide variety of psychological problems, } \\
\text { such as panic disorder, anxiety and depression on Chinese population. } \\
\text { Women reporting higher levels of distress in mental health due to the pandemic than men. }\end{array}$ \\
\hline $\mathrm{Ga}$ & Emotional distress can be caused by a higher media exposure of pande \\
\hline $\begin{array}{r}\text { Francis, Moit } \\
\text { Keller }\end{array}$ & $\begin{array}{l}\text { Changes in daily routine and interruptions in people mental health care, can be factors that } \\
\text { can cause a deterioration in mental health. } \\
\text { Studies suggest a connection between stressful life events and the development and course } \\
\text { of depressive symptoms. } \\
\text { According to Francis, Moitra, Dyck, \& Keller (2012), some etiological theories propose that } \\
\text { stressful life events are significative to the development and preservation of generalized } \\
\text { anxiety disorder, as same of the worry about these events. }\end{array}$ \\
\hline $\begin{array}{c}\text { Cornelius, van der } \\
\text { Boer, Brouwer, \& } \\
{[18]}\end{array}$ & $\begin{array}{l}\text { Because of confinement, people with physical health conditions have reduced access to } \\
\text { health care, which possible exacerbate their physical condition, consequently increasing their } \\
\text { risk for mental health difficulties. }\end{array}$ \\
\hline Lee Kang, Cho Kim, Park, [19] & $\begin{array}{l}\text { During the acute infection stage during a pandemic could result in serious psychological } \\
\text { distress. } \\
\text { While suffering a chronic disease, studies have confirmed a notably increase rates of } \\
\text { depression in patients, because of that we can expect COVID-19 positive patients will be at } \\
\text { risk of depression as well. }\end{array}$ \\
\hline $\begin{array}{c}\text { Alonzi S, La Torre A, \& } \\
\text { Silverstein MW [20] }\end{array}$ & $\begin{array}{l}\text { Subsequent the COVID-19 pandemic declaration was established that women and nonbinary } \\
\text { individuals, both with preexisting physical and mental health conditions, presented higher } \\
\text { levels of depression and anxiety. }\end{array}$ \\
\hline
\end{tabular}

Table 1: Examples of mental health threats associated with COVID-19 pandemic.

Moreover, is normal, during and after confinement [9], a great amount of people may develop symptoms, especially when greater adaptability was necessary and in a short time. Among the most frequent are the manifestation of restlessness, insomnia, attention problems, concentration and memory, emotional lability (exaggerated changes in mood) or circular thoughts about illness [5]. Another stressor we can mention is the constant changes in the information about COVID-19 forms of transmission, symptomatic or asymptomatic agents, changes in the perception of the severity of the disease and the information posted at the Internet without knowing if it is a valid source. This will possible generate great insecurity in the population and greater anxiety that could be studied in the future. In addition, we need to consider the economic impact, the one will be a considerable risk factor for Anxiety or Mood Disorders, being the most expected diagnoses caused by this type of hazardous situations [5]. Likewise, the exposure to a disaster of a large scale like this one has been associated with the increase of domestic violence, child abuse, posttraumatic stress disorders, depression, and substance use disorder [9]. Substance use disorder is other significant aspect we have to consider, as we know this public health issue came before the pandemic. Like example the opioid overdoses, is the epidemic at the United States [9] and other places were facing before COVID-19, and if we consider the confinement and new policies of social distancing as a new access barrier to this part of the population, we can anticipate the creation 


\section{Psychology \& Psychological Research International Journal}

of this social isolation can lead in detrimental outcome to opioid users. What studies propose, opioid users are associated with poor mental health or comorbid with mental health conditions and that is an increase factor to the risk of overdosing alone [10-14].

This pandemic helps us to realize that we, with all the scientific progress and developments, was not prepared to deal with COVID-19 and it associated issues but, at the same time, gave us the tools to identify our areas for improvement. As mental health professionals, we need to be aware of the importance of providing a psychological first aid when facing a disaster, this is an essential care component for population that have been victims of emergencies and disasters ${ }^{[10]}$ as mentioned. Also, is necessary to create awareness to our leaders and to the population about the importance of a healthy mental status. We need to create protocols for delivering the population a better psychosocial support and promote self-care, correspondingly, provide them with the most accurate psych education and easy to understand [21]. Moreover, the population have the right to get a safe access to health services and it is necessary to develop public policies to preventing this type of phenomenon and did not let the population be in the dilemma of selecting between having physical or mental health instead to work with both at the same time using an interdisciplinary team of health professionals. As conclusion, we will not be able to control to be exposed to another pandemic but what we can control being better prepared.

\section{References}

1. Morens DM, Breman JG, Calisher CH, Doherty PC, Hahn BH, et al. (2020) The Origin of COVID-19 and Why It Matters. The American Journal of Tropical Medicine and Hygiene 103(3): 955-959.

2. Ornell F, Schuch JB, Sordi AO, Paim Kessler FH (2020) "Pandemic fear" and COVID-19: mental health burden and strategies. Revista Brasileira de Psiquiatria 42(3): 232-235.

3. Tucci V, Moukaddam N, Meadows J, Shah S, Galwankar SC, et al. (2017) The Forgotten Plague: Psychiatric Manifestations of Ebola, Zika, and Emerging Infectious Diseases. Journal of Global Infectious Diseases 9(4): 151-156.

4. Reardon S (2015) Ebola's mental-health wounds linger in Africa. Nature 519(7541): 13-14.

5. Gutiérrez Salegui I (2020) Consecuencias psicológicas de la pandemia Covid-19. Tiempo de Paz 137: 116-124.

6. Ironson G, Hylton E, Gonzalez B, Small B, Freund B, et al. (2020) Effectiveness of three brief treatments for recent traumatic events in a low-SES community setting. Psychological Trauma: Theory, Research, Practice, and Policy.

7. Jessica Russo, PhD, et al. (2017) MLA (Modern Language Assoc.) DSM-5® and Family Systems. Springer Publishing Company.

8. Jessica Russo P, Kelly Coker JP, Jason H King P (2017) APA (American Psychological Assoc.) DSM-5® and Family Systems. Springer Publishing Company.

9. Henry BF, Mandavia AD, Paschen-Wolff MM, Hunt T, Humensky JL, et al. (2020) COVID-19, mental health, and opioid use disorder: Old and new public health crises intertwine. Psychological Trauma: Theory, Research, Practice, and Policy 12(S1): S111-S112.

10. Jacobs J, Oosterbeek M, Tummers LG, Noordegraaf M, Yzermans CJ, et al. (2019) The organization of post-disaster psychosocial support in the Netherlands: a meta-synthesis. European Journal of Psychotraumatology 10(1): 1-11.

11. Ellis R, Wynter R, Light R (2020) Body and Mind. Are we adequately prepared for the toll this pandemic will take on mental health? History Today 70(10): 90-93.

12. Wu L, Guo X, Shang Z, Sun Z, Jia Y, et al. (2020) China experience from COVID-19: Mental health in mandatory quarantine zones urgently requires intervention. Psychological Trauma: Theory, Research, Practice, and Policy 12(S1): S3-S5.

13. Alonzi S, La Torre A, Silverstein MW (2020) The psychological impact of preexisting mental and physical health conditions during the COVID-19 pandemic. Psychological Trauma: Theory, Research, Practice, and Policy 12(S1): S236-S238.

14. Koushik NS (2020) A population mental health perspective on the impact of COVID-19. Psychological Trauma: Theory, Research, Practice, and Policy 12(5): 529-530.

15. Fitzpatrick KM, Harris C, Drawve G (2020) Fear of COVID-19 and the mental health consequences in America. Psychological Trauma: Theory, Research, Practice, and Policy 12(S1): S17-S21.

16. Alonzi S, La Torre A, Silverstein MW (2020) The psychological impact of preexisting mental and physical health conditions during the COVID-19 pandemic. Psychological Trauma: Theory, Research, Practice, and Policy 12(S1): S236-S238. 
17. Qiu J, Shen B, Zhao M, Wang Z, Xie B, et al. (2020) A nationwide survey of psychological distress among Chinese people in the COVID-19 epidemic: Implications and policy recommendations. General Psychiatry 33(2): e100213.

18. Garfin DR, Silver RC, Holman EA (2020) The novel coronavirus (COVID-2019) outbreak: Amplification of public health consequences by media exposure. Health Psychology 39(5): 355-357.

19. Francis JL, Moitra E, Dyck I, Keller MB (2012) The impact of stressful life events on relapse of generalized anxiety disorder. Depression and Anxiety 29(5): 386-391.

20. Cornelius LR, van der Klink JJL, de Boer MR, Brouwer S, Groothoff JW (2016) High prevalence of early onset mental disorders among long-term disability claimants. Disability and Rehabilitation: An International, Multidisciplinary Journal 38(6): 520-527.

21. Lee SM, Kang WS, Cho AR, Kim T, Park JK (2018) Psychological impact of the 2015 MERS outbreak on hospital workers and quarantined hemodialysis patients. Comprehensive Psychiatry 87: 123-127. 